\title{
O desafio de ensinar história em cursos de relações internacionais
}

\author{
Günther Richter Mros \\ Professor no Departamento de Economia e Relações Internacionais \\ Universidade Federal de Santa Maria - UFSM \\ gunther.mros@ufsm.br
}

\footnotetext{
Como citar este artigo: MROS, Günther R.. "O desafio de ensinar história em cursos de relações internacionais", Intelligere, Revista de História Intelectual, nº, pp. 178-190. 2020. Disponível em $<$ http://revistas.usp.br/revistaintelligere $>$. Acesso em dd/mm/aaaa-
}

Resumo: O presente artigo aborda o desafio que existe no ensino de História para cursos de Relações Internacionais. Trata-se de uma breve reflexão sobre conceitos-chave da disciplina de História das Relações Internacionais e de sua aplicabilidade em uma disciplina oferecida no curso de graduação da Universidade Federal de Santa Maria. As reflexões aqui contidas foram inspiradas na carreira exemplar do Professor Emérito da Universidade de Brasília, Amado Luiz Cervo, a quem o autor deve muito de sua formação e escolhas profissionais.

Palavras-chave: Educação superior; História; Relações Internacionais; Metodologias de ensino.

The challenge of teaching classes of history for undergraduate courses of international relations

Abstract: This article addresses the challenge that exists in teaching classes of History for International Relations courses. This is a brief reflection on key concepts of the discipline of History of International Relations and its applicability in a discipline offered in the undergraduate course at the Federal University of Santa Maria. The reflections contained here were inspired by the exemplary career of Professor Emeritus of the University of Brasilia, Amado

${ }^{1}$ Günther Richter Mros é doutor em História e professor adjunto no Departamento de Economia e Relações Internacionais da Universidade Federal de Santa Maria (UFSM). Lidera o Grupo de Estudos em Instituições e Processos Decisórios nas Relações Internacionais (GEIPRI), registrado no Diretório de Grupos de Pesquisa do CNPq. E-mail: gunther.mros@ufsm.br. Orcid: https://orcid.org/0000-0002-1111-0956. 
Luiz Cervo, to whom the author owes much of his training and professional choices

Keywords: Higher education; History; International Relations; Teaching methodologies.

\section{Introdução}

O estudo sistematizado das relações internacionais (RI) nas universidades brasileiras teve início com o curso de graduação da Universidade de Brasília (UnB), em 1974. Desde os primeiros anos, a área de História tem contribuído como pilar de sustentação - junto com outras áreas como Direito, Economia, Ciência Política e Geografia - para as pesquisas e a consolidação do campo de conhecimento das RI. As disciplinas de História são parte relevante dos cursos de RI, presentes nas diretrizes nacionais por meio de ao menos duas nomenclaturas: História das RI (HRI) e História da Política Externa Brasileira (HPEB).

O desafio de um professor dessas disciplinas, porém, é o de superar a factualidade cronológica herdada da educação básica, com que chega a maior parte dos estudantes ao ensino superior. O pensar histórico é percebido, em geral, como acumulação de fatos e datas. A desmistificação do tempo histórico ocorre com maior tranquilidade em cursos de graduação em História, mas nas RI, assim como em outras áreas, há equívoco em perceber a História como ciência auxiliar para comprovação de hipóteses e legitimar deduções, como se meros prólogos do presente fossem as vozes do passado.

Destarte, o que propomos neste artigo é refletir sobre uma experiência adotada no curso de RI da Universidade Federal de Santa Maria (UFSM), no ano de 2019. O curso da UFSM existe desde o ano de 2009, mas passou por ampla reforma do Projeto Pedagógico (PPC), em 2018, dividindo a disciplina de Política Externa Brasileira (PEB) em duas: HPEB e Política Externa no Brasil Contemporâneo (PEBC). Nessa reforma do PPC as duas disciplinas que existiam de HRI se transformaram em três, sendo duas com caráter mais cronológico e factual, e uma novidade, uma disciplina totalmente voltada à discussão epistemológica da História das RI. 
Conquanto nas duas primeiras disciplinas de HRI haja a preocupação com o caráter holístico da História, o andamento da disciplina com conteúdo que se estende desde a Paz de Vestefália, em 1648, até o fim da URSS, em 1991, obriga o docente a seguir um padrão já conhecido pelos estudantes de absorção do conhecimento histórico. A terceira disciplina, entretanto, chamada HRI C, possibilita a ressignificação do saber histórico por parte dos jovens profissionais em formação na área de RI.

O artigo está dividido em duas partes. Primeiramente vamos estabelecer os marcos conceituais e as categorias analíticas apresentadas aos alunos, bem como os questionamentos-chave na relação entre o que conheciam e uma nova forma de leitura do tempo.

$\mathrm{Na}$ segunda e última parte de nossa breve reflexão sobre o ensino de História em um curso de RI, trataremos da resposta à disciplina por parte dos estudantes, por meio da análise de suas escolhas de pesquisa para o trabalho final da disciplina. De maneira geral, apresentaremos a forma como a disciplina foi organizada e o trabalho que foi feito para estimular debates e novas formas de pensar os nexos causais de tempo e espaço.

\section{Um apanhado teórico-conceitual}

Inicialmente, é preciso dizer que o autor desse artigo deve boa parte de sua formação analítica à convivência com o professor Dr. Amado Luiz Cervo, desde a orientação no mestrado até as inúmeras conversas que se mantêm até hoje. Cervo foi um dos responsáveis pela consolidação dos estudos de história das RI no Brasil, se dedicando por muitos anos ao seu "livrão", como ele mesmo diz, em parceria com o colega professor Dr. Clodoaldo Bueno (CERVO ; BUENO, 2015). Cervo traz consigo uma ênfase na construção de conceitos (CERVO, 2008a e 2008b) em oposição ao caráter tendencioso das clássicas teorias de RI, a partir da leitura das idiossincrasias das relações internacionais do Brasil e da América Latina (CERVO, 2001).

A leitura das particularidades de uma nação nas suas relações internacionais é herança da escola francesa de estudos de HRI (SARAIVA, 2008, pp. 11-16). Foi o francês Pierre Renouvin quem elaborou o conceito de 
forças profundas, para distinguir a análise excessivamente documental e estatal da história diplomática da nova abordagem societária da HRI. Trata-se, dessa forma, de um sistema de multicausalidades que atua sobre as relações internacionais. São ocultas e de difícil percepção daqueles que vivem o momento histórico em que elas ocorrem. Emanam das coletividades humanas e dependem de um processo de tomada de consciência, o que faz desse conceito uma inovação (RENOUVIN ; DUROSELLE, 1967, pp.9-297).

Elemento essencial do historiador, "o tempo adere ao seu pensamento como a terra à pá do jardineiro" (BRAUDEL, 1965, p. 288) e eis aí um dos desafios no ensino de história. O tempo histórico não segue uma linha reta como nos calendários ou como na visão positivista de progresso. A diacronia, portanto, precisa ser deixada de lado por alguns momentos para que o historiador consiga tecer uma teia semântica com as particularidades de seu objeto de estudo.

Os eventos históricos presentes em uma ordem sincrônica, nesse sentido, deixam de ser elemento encapsulado por hierarquias pueris para se tornarem propulsores de significados diversos. Para François Dosse (2013, p.12) "o acontecimento não é um simples dado que basta coletar [...], é uma construção que remete ao conjunto do universo social como matriz da constituição simbólica do sentido". Isto é, por trás de cada evento existe um espaço de experiência e um horizonte de expectativas, tal como estabeleceu Koselleck como categorias analíticas (2006, pp. 305-327).

Essa percepção de que o tempo histórico nos remete ao aspecto relacional dos eventos (MROS, 2019, pp. 73-94) é fundamental para se buscar a leitura crítica das relações internacionais do Brasil e de seu entorno geoestratégico. Os jovens estudantes, mesmo aqueles que não pretendam seguir o caminho da pesquisa histórica, ganham nova percepção do tempo em que estão inseridos, e também de seus papéis enquanto partes de uma enorme rede semântica sob constantes ressignificações.

Dentro dessa perspectiva, o método de trabalho do historiador, de construção de narrativas mais indutivas que dedutivas — pois "na indução, a conclusão está para as premissas como o todo está para as partes. De verdades 
particulares concluímos verdades gerais" (CERVO; BERVIAN; SILVA, 2007, p. 44) —, se inicia a partir de uma curiosidade própria do tempo em que está inserido.

John Lewis Gaddis (2004, p. 48) ao mencionar uma conversa com o historiador William H. McNeill, sobre metodologia, ouviu do mesmo a seguinte explicação:

Eu fico curioso sobre um problema e começo a ler sobre isso. $\mathrm{O}$ que eu leio me leva a redefinir o meu problema. Redefinir o problema me leva a mudar a direção do que eu estou lendo. Isso, por sua vez, ainda remodela o problema, o que depois redirecionará a minha leitura. Eu procedo voltando e adiantando dessa forma até que sinta que está certo, e então eu escrevo o texto e o envio à minha editora.

O problema comum dessa estratégia, quando apresentada aos alunos de RI, é que da curiosidade inicial parte-se para o estabelecimento de hipóteses, antes mesmo de a pergunta norteadora da investigação histórica estar amadurecida. Outrossim, é preciso alguns anos de experiência para que o pesquisador consiga segurar o ímpeto de responder primeiro e perguntar depois, lançando olhar metódico e estratificado sobre seu objeto de pesquisa.

Koselleck (2014) propôs os estratos do tempo como forma de superação da organização narrativa, tradicionalmente dividida em sincronia e diacronia, dialogando com Braudel (2016) acerca das longas, médias e curtas durações por meio de leitura antropológica de três estratos básicos inseridos no conceito de experiência: as singularidades, as repetições e as experiências que ultrapassam os planos individuais. "A expressão 'estratos do tempo' remete a formações geológicas [em sentido metafórico] que remontam a tempos e profundidades diferentes, que se transformam e se diferenciam umas das outras em velocidades distintas [...]." (KOSELLECK, 2014, p. 19). Dessa forma, entendemos que as ressignificações no tempo diacrônico e no recorte sincrônico ocorrem sob múltiplas sobreposições causais — os estratos do tempo.

Estabelecida a relação entre tempo e objeto, a narrativa se torna o elemento seguinte a ser apresentado aos jovens historiadores de RI. E nesse 
passo do trabalho evoca-se outro ponto levantado por Amado Cervo em seus escritos: a necessidade de se criar conceitos.

José d'Assunção Barros (2017), ao tecer considerações sobre o anacronismo, destaca que somente a História põe o pesquisador sob especificidade de duas temporalidades distintas, a sua e a do objeto em exame. De fato, poder-se-ia dizer que o problema é ainda mais complexo quando há três ou mais temporalidades a depender de quantas outras vezes um mesmo objeto fora analisado ao longo dos anos. Nesse sentido, dadas as distintas temporalidades, é necessário levarmos em conta as idiossincrasias e os conceitos resultantes desse processo de contato entre diferentes periodizações.

Amado Cervo (2008b) confrontou conceitos e teorias mediante hipótese segundo a qual conceitos e teorias exercem papeis diferenciados no campo de estudo das RI. O suposto alcance explicativo universal das teorias, para Cervo, é forjado - de maneira consciente ou não, por acadêmicos de países hegemônicos do sistema internacional —, enquanto "os conceitos expõem as raízes nacionais ou regionais sobre as quais se assentam e se recusam estar investidos de alcance explicativo global" (CERVO, 2008b, p. 8). Em sua gênese, os conceitos detêm quatro características essenciais: são uma construção social; uma expressão da historicidade; incluem uma mensagem positiva; e são revolucionários, no sentido de produzirem o novo frente a fenômenos preexistentes (CERVO, 2008b, pp. 22-23).

Esses quatro elementos elencados possibilitam uma didática no ensino de História para estudantes de RI que aponta caminhos para a produção de trabalhos originais e ensina a pensar não apenas o objeto em si, mas também a função do historiador como construtor de entendimento social das realidades que o cercam. São os conceitos que ressignificam o estudo das RI por meio das lentes da História.

Cabe aqui, no entanto, conceituarmos o termo ressignificação. Esse termo carrega ao mesmo tempo a carga semântica de algo que foi modificado e o teor da modificação em si. Essa carga semântica, também chamada de sentido, "é um produto do espírito humano, [...] é o critério fundamental, com o qual o homem tanto regula sua relação para consigo mesmo e para com os 
outros, quando decide sobre suas intenções e sobre a intencionalidade de sua vontade" (RÜSEN, 2015, p. 42). A ressignificação é ato de lançar olhar sobre o objeto histórico tendo a cultura - entendida aqui como bagagem prévia do indivíduo que olha, bagagem essa conformada pela memória: memória individual, somada à memória coletiva de seu entorno imediato - como fator de mudança social e como agente de mudança da história (PESAVENTO, 2008, pp. 30, 66 e 95). "Ressignificar [, portanto, ] implica dar novo sentido às palavras, relações, coisas, práticas e rituais" (REIS, 2006, p. 12).

Todo o apanhado teórico-conceitual que apresentamos nestas linhas serve muito pouco se não soubermos ressignificar também a função do saber histórico e a aplicabilidade da herança deixada por inúmeros trabalhos e pesquisas voltados para a evolução deste campo do conhecimento humano. Em seguida trataremos, portanto, de uma abordagem que propusemos aos alunos de RI do curso da UFSM. Assim, o que descreveremos a seguir foi uma experiência didática, uma metodologia em aberto e em constante transformação.

\section{Uma disciplina sempre em construção e a resposta do alunado}

No ano de 2019 começamos a ministrar a disciplina História das RI C na UFSM, sendo oferecida como terceira na sequência de disciplinas de História, no quarto semestre dos alunos do curso de graduação. O objetivo da disciplina, segundo a ementa elaborada no novo PPC, é de desenvolver a percepção acerca da história das relações internacionais por meio da historiografia internacional e brasileira e por meio dos principais processos e conceitos históricos, com foco no sistema internacional ocidental contemporâneo.

O programa da disciplina está dividido em quatro unidades: aspectos fundamentais; história diplomática e as escolas de pensamento em HRI; instrumentalidade da História nas teorias de RI; e contemporaneidade e relações internacionais.

$\mathrm{Na}$ unidade primeira os alunos são apresentados a aspectos ontológicos da disciplina e são convidados a refletir sobre aspectos relacionais, tais como: 
foco, autonomia, autorreferência e o modus operandi do historiador. Ao final dessa unidade a discussão passa pelas funções do saber histórico e com a tentativa de se responder sobre o porquê de se estudar história em um curso de RI.

$\mathrm{Na}$ segunda unidade passamos à apresentação da herança recebida da História Diplomática e mergulhamos nas escolas de pensamento em HRI. Os franceses com seu pioneirismo conceitual, as visões sistêmicas de uma história internacional dos britânicos $\mathrm{e}$ as abordagens italiana, suíça, alemã e estadunidense são o caminho pedagógico da disciplina. A unidade encerra com a apresentação da contribuição latino-americana, quando se tem o contato com os textos dos principais nomes brasileiros, argentinos, chilenos e demais intelectuais que se puseram a refletir sobre o pensamento de RI na América Latina.

A terceira unidade tem por objetivo abordar a instrumentalidade dos estudos de História nas principais teorias clássicas e contemporâneas de RI. A finalidade aqui é demonstrar os diferentes usos e apropriações, muitas vezes indevidos, do recurso à legitimidade historiográfica para construir narrativas teóricas com suposta universalidade.

Por fim, na quarta unidade, os alunos trabalham com textos relacionados a temáticas bastante recentes no campo das RI. O estudo dos conceitos, o papel das potências nos tempos históricos do sistema internacional e a história comparada - como método muito abrangente de enfoque de investigação histórica.

Comparar é "forma específica de propor e pensar questões" (BARROS, 2014, p. 17), em alguns casos com espacialidades distintas, como dois países, por exemplo, em outros com "duas sociedades relativas ao mesmo recorte espacial [...] em temporalidades diferenciadas" (BARROS, 2014, p. 56).

Ainda abordamos, ao fim e ao cabo, as recentes reflexões acerca da Global History e os estudos de uma História do tempo presente, do mundo pósGuerra Fria. Autores como Crossley (2015, pp. 137-138 e 145) e Conrad (2016, pp. 1-16) definem História Global como sendo resultado de 
metodologias não eurocêntricas, para além da abordagem do Estado-Nação e de crescimento historiográfico majoritário a partir dos anos 1990.

Pensamos que esse conteúdo não seria facilmente absorvido com uso exclusivo das aulas expositivas e com debates em sala de aula a partir das leituras dos textos. Por esse motivo, optamos por adotar como método de ensino propor a redação de um artigo como nota final da disciplina.

A proposta foi de um artigo em dupla, o que gerou vinte e dois artigos dos mais variados temas. Inicialmente, a ideia era que os alunos tivessem total liberdade na escolha dos objetos de pesquisa, escolhendo-os a partir de suas vivências e de suas visões de mundo, desde que esses temas pudessem valer-se do método histórico apresentado a eles e que estivesse inserido no campo de estudos de HRI, seja em um aspecto mais societário e transnacional - o que foi a escolha de muitos —, seja em uma leitura estatocêntrica típica das RI.

Foi apresentado aos alunos o seguinte passo a passo:

1) escolha de título provisório, nomes dos integrantes da dupla e definição, em um parágrafo, sobre o objeto da investigação;

2) escolha de uma fonte documental e onde a encontrou — arquivos, hemerotecas, sites de bibliotecas, etc. Explicar em um parágrafo a relação do documento com o objeto;

3) elencar cinco textos (livros, artigos ou teses) de cinco diferentes autores, contextualizando-os ao objeto e à fonte documental;

4) com todas as etapas anteriores vencidas, definir a pergunta de pesquisa;

5) por fim, a redação do artigo.

As aulas de HRI C ocorreram em encontros de uma vez por semana, com duração de quatro horas cada. Adotamos como praxe dar aula expositiva nos dois primeiros horários e, em seguida, nas duas horas restantes, seguíamos 
todos para o laboratório de informática, onde cada aluno teve acesso a um computador logado na internet. Esse foi um ponto fundamental para a experiência ter sido bem-sucedida.

Desde o início do semestre houve incentivo para que as duplas de alunos pesquisassem sites diversos e textos dos mais variados sobre a temática escolhida por eles para, mais ou menos na metade do semestre, terem tido a firmeza e a conviçcão de estabelecerem a pergunta de pesquisa.

Os temas foram muitos e diversos: feminismo nas obras de Frida Kahlo; militância LGBTQ a partir do evento de Stonewall — viés bastante societário e transnacional -; histórias em quadrinhos do Tintim — sobre o racismo colonial belga —; invasão do Afeganistão pela URSS em 1979 — feito por um aluno afegão —; Operação Condor; Tratado de Iguaçu; Guerra do Paraguai; desenhos de Walt Disney no contexto da Segunda Guerra Mundial; influência francesa na arquitetura de Fortaleza - CE, na Primeira Guerra Mundial; Tratado de Nanquim e a Guerra do Ópio; Haiti e o Caricom — feito por dois alunos haitianos —; Tratado Versalhes; MINUSTAH — feito por dois outros alunos haitianos —; processo de descolonização do Saara Ocidental; sufrágio feminino; análise da atuação do Fundo das Nações Unidas para a Infância (UNICEF) no combate ao uso de crianças-soldado em conflitos armados em Sierra Leoa; Avós da Plaza de Mayo; crises políticas na Venezuela; uso da imagem de Che Guevara como símbolo para causas diversas; processo de independência no Sudão do Sul; futebol e política nas Copas do Mundo; o papel da mídia na Guerra do Golfo; e imigração italiana para a região da Quarta Colônia, no entorno de Santa Maria - RS , em fins do Século XIX.

As fontes pesquisadas pelos alunos foram igualmente diversas: tratados, cartas, relatórios, jornais, fotos, quadros e revistas em quadrinhos. O exercício de ligar essas fontes a textos de diferentes autores e estabelecer teias semânticas relacionais com atenção às duas categorias analíticas de Koselleck — espaço de experiência e horizonte de expectativa - trouxe aos alunos uma percepção diferente do valor do tempo histórico para o estudo das RI. Nesse sentido, os 
artigos mostraram ser mais que um mero exercício e abriram portas e interesses de pesquisa que se mantêm em alguns dos estudantes.

A disciplina continuará sendo oferecida anualmente, de maneira obrigatória no currículo do curso, e deverá passar por alguns ajustes. O mais importante, no entanto, é o fato de o saber histórico continuar sendo um pilar fundamental para a construção do conhecimento na área de RI como um todo.

\section{Considerações finais}

A experiência com a disciplina de HRI que acabamos de relatar dependeu do envolvimento dos alunos - nem todos em um mesmo grau de dedicação, é verdade, mas sem que isso invalidasse o experimento pedagógico — e da infraestrutura dos laboratórios de informática oferecida pelo Centro de Ciências Sociais e Humanas (CCSH) da UFSM. Acreditamos que as Ciências Humanas, de maneira geral, e as RI, mais especificamente, como Amado Cervo tem demonstrado durante toda a sua carreira, têm o papel de transformar percepções e realidades concretas por meio do pensamento crítico.

O pragmatismo próprio da área de RI exige que futuros profissionais na área tenham algo a contribuir para um mundo em constante ressignificação, tal como mencionou Ortega y Gasset (2004, p. 757),"yo soy yo y mi circunstancia, y si no la salvo a ella no me salvo yo". A História, nesse cenário, continuará sendo a fiadora do homem no tempo e no espaço.

\section{Referências}

BARROS, J. d'A. História comparada. Petrópolis, RJ: Vozes, 2014.

BARROS, J. d'A. Os conceitos na história: considerações sobre o anacronismo, Ler História [online], 71 | 2017. Disponível em: http://journals.openedition.org/lerhistoria/2930;

DOI: 10.4000/lerhistoria.2930. Acesso em 19 out. 2019.

BRAUDEL, F. História e Ciências Sociais: a longa duração. Revista de História. São Paulo. N. 62, abril-junho, vol. XXX, ano XVI, 1965, pp. 261-294. 
BRAUDEL, F. O Mediterrâneo e o Mundo Mediterrâneo na época de Filipe II (Volume 1). São Paulo: EdUSP, 2016.

CERVO, A. L. Relações internacionais da América Latina: velhos e novos paradigmas. Brasília: IBRI, 2001.

CERVO, A.; BERVIAN, P. A.; SILVA, R. da. Metodologia científica. 6. ed. São Paulo: Pearson, 2007.

CERVO, A. Inserção Internacional: formação dos conceitos brasileiros. São Paulo: Saraiva, 2008a.

CERVO, A. Conceitos em relações internacionais. RBPI, Brasília, ano 51, $\mathrm{n}^{\circ}$ 2, p. 8-25, 2008b.

Cervo, A. ; BUEnO, C. História da Política Exterior do Brasil. 5. ed. Brasília: UnB, 2015.

CONRAD, S. What Is Global History? Princeton - New Jersey: Princeton University Press. Edição do Kindle, 2016.

CROSSLEY, P. K. O que é História Global? Tradução de Vera Joscelyne. Petrópolis, RJ: Editora Vozes, 2015.

DOSSE, F. Renascimento do acontecimento: um desafio para o historiador entre esfinge e fênix. Tradução de Constancia Morel. São Paulo: Unesp, 2013.

GADDIS, J. L. Landscape of history: how historians map the past. Oxford: USA Trade, 2004.

KOSELLECK, R. Futuro passado: contribuição à semântica dos tempos históricos. Rio de Janeiro: PUCRIO, 2006.

KOSELLECK, R.. Estratos do tempo: estudos sobre história. Rio de Janeiro: Contraponto Editora, 2014.

MROS, G. R. O Brasil nas Guerras dos outros: o interesse nacional em meio a ressignificações sistêmicas $(1914$ - 1919 \& 1930 - 1945). 2019. 229 f. Tese (Doutorado em História). Universidade Federal de Santa Maria, Santa Maria RS, Brasil.

ORTEGA Y GASSET, J. Obras completas, Vol. I. Ed. Taurus/Fundación José Ortega y Gasset, Madrid, 2004.

PESAVENTO, S. J. História e história cultural. 2.ed. Belo Horizonte: Autêntica, 2008.

RENOUVIN, P.; DUROSELLE, J-B. Introdução à História das Relações Internacionais. São Paulo: DIFEL, 1967. 
REIS, L. M. "Africanos no Brasil: saberes trazidos e ressignificações culturais. In: Cadernos de História, Belo Horizonte, vol. 8, n. 10, pp. 11-23, $2^{\circ}$ sem. 2006.

RÜSEN, J. Teoria da história: uma teoria da história como ciência. Curitiba: Ed. UFPR, 2015.

SARAIVA, J. F S. (Org.). História das Relações Internacionais Contemporâneas: da sociedade internacional do século XIX à era da Globalização. São Paulo: Saraiva, 2008. 